\title{
HUBUNGAN PENGETAHUAN DAN SIKAP SISWA SEKOLAH DASAR TENTANG SANITASI DASAR DENGAN TINDAKAN PERILAKU HIDUP BERSIH DAN SEHAT \\ DI SD NEGERI 046579 DESA LAU PERANGGUNEN KAB . KARO
}

\author{
Rio Ferdi Yuandra, Cintya Nathasa Br Ginting \\ Institut Kesehatan Deli Husada Deli Tua \\ e-mail : rio.skm.mkm@gmail.com
}

\begin{abstract}
All health behaviors are carried out because of personal awareness so that the family and all members are able to help themselves in the health sector and have an active role in community activities. Clean and Healthy Living Behavior is basically an effort to transmit experiences about healthy living behavior through individuals, groups or the wider community using communication channels as a medium for sharing information.. This type of research is a type of quantitative research with an observational method using a cross sectional approach with a population of all students in class IV, V, and VI who are in SD Negeri 046579 in Lau Peranggunen Kab.Karo, which is 82 people. The sample in this study is a total sampling technique. Based on the instruments in this study are questionnaires, data analysis techniques used the chisquare statistical test. Based on the chi-square analysis, it was found that there was a relationship between knowledge and attitudes of elementary school students with PHBS actions which amounted to ( $p=0.046)$, there was a significant relationship between knowledge with PHBS actions. and the relationship between basic sanitation attitudes and PHBS actions were obtained as basic $(p=0.040)$, there was a significant relationship between PHBS attitudes and actions. Lau Kab karo residents to increase the knowledge, attitudes and actions of PHBS in the school environment in the teaching and learning process so that they understand and know the benefits for themselves and their environment.
\end{abstract}

Keywords: clean and healthy behavior, attitude and knowledge.

\section{PENDAHULUAN}

Pembangunan di masa depan perlu dijaga dan dilindungi terutama kesehatan anak sekolah. Tempat penuaran penyakit salah satunya terdapat di sekolah. Usia yang rawan terkena penyakit salah satunya pada usia anak sekolah dasar. (Umar, 2010).
Dalam pembelajaran Sekolah harus harus memiliki lingkungan yang sehat. Aspek lingkungan fisik dilihat pada fasilitas ruangan dan bangunan, ventilasi dan pencahayaan, kepadatan kelas, jarak papan tulis dengan siswa, ketersediaan toilet, kualitas dan kuantitas meja dan kursi siswa, 
tempat cuci tangan, tempat sampah dan pengelolaan sampah dan air bersih, serta kantin sehat. Lingkungan non fisik meliputi perilaku guru dan siswa di sekolah agar mendorong dan membiasakan siswa untuk berperilaku hidup bersih dan sehat. (Kemendikbud, 2012).

Perilaku Hidup Bersih dan Sehat di Sekolah adalah sekumpulan perilaku yang dipraktikan oleh peserta didik, guru dan masyarakat di lingkungan Sekolah atas dasar kesadaran sebagai hasil pembelajaran, sehingga secara mandiri mampu mencegah penyakit, meningkatkan kesehatan, serta berperan aktif dalam mewujudkan lingkungan sehat (Kemenkes, 2014)

Periku hidup bersih dan sehat (PHBS) untuk anak usia SD dimulai dengan membentuk kebiasaan sikat gigi dengan benar, mencuci tangan, serta membersihkan kuku dan rambut. PHBS yang sangat sederhana tersebut akan mengurangi risiko terkena penyakit. Penyakit yang akan muncul akibat rendahnya PHBS antara lain cacingan, diare, sakit gigi, sakit kulit, gizi buruk dan lain sebagainya yang pada akhirnya mengakibatkan rendahnya derajat kesehatan Indonesia (Pramono M, 2011).

Munculnya berbagai penyakit yang sering menyerang anak usia sekolah (usia 6-10), umumnya berkaitan dengan Perilaku Hidup Bersih dan Sehat (PHBS), Anak sekolah merupakan generasi penerus bangsa yang perlu di jaga, di tingkatkan dan dilindungi kesehatannya. Jumlah anak usia sekolah yang cukup besar yaitu $30 \%$ dari jumlah penduduk di Indonesia oleh karena itu, penanaman nilai-nilai PHBS disekolah merupakan kebutuhan mutlak bagi anak sekolah (Proverawati \& Rahmawati, 2012).

Menurut survey awal di SDN 046579 Desa Lau Peranggunen Kabupaten Karo, dari 20 siswa yang di wawancarai ada 5 siswa yang mengetahui apa itu sanitasi dasar dan perilaku hidup bersih dan sehat (PHBS) dan sudah melakukkan dalam kehidupan sehari-hari mereka, dan ada 4 orang siswa yang mengetahui apa itu sanitasi dasar dan PHBS Tetapi tidak menerapkannya dalam keseharian mereka,dan ada 11 orang siswa yang sama sekali tidak mengetahui apa itu sanitasi dasar PHBS, dikatakan tidak mengetahui karena wawancara yang dilakukan dan terlihat dari sikap siswa yang masih membuang sampah sembarangan, kuku siswa tidak di potong, sering bermain di lapangan dan sebelum memakanan makanan tidak mencuci tangan terlebih dahulu. Berdasarkan uaraian di atas peneliti ingin mengetahui Hubungan Pengetahuan dan Sikap Siswa Sekolah Dasar tentang Sanitasi Dasar dengan Tindakan PHBS di SDN 046579 Desa Lau Peranggunen Kab.Karo.

\section{METODE}

Penelitian ini dilakukan dengan jenis Penelitian Kuantitatif. Metode yang digunakan Observasional 
dengan Desain Cross Sectional. Sampel dalam penelitan ini adalah keseluruhan siswa kelas IV, V, VI sebanyak 82 orang.

\section{HASIL}

\section{Analisis Univariat}

Distribusi Frekuensi siswa dapat diamati dalam penelitian adalah pengetahuan, sikap dan tindakan siswa. Hasil penelitian kemudian dinyatakan pada tabel 1 berikut ini.

Tabel 1. Distribusi Frekuensi pengetahuan, sikap, dan tindakan siswa

\begin{tabular}{lcc}
\hline Variabel & n & \% \\
\hline Pengetahuan & & \\
Kurang & 72 & 87,8 \\
Baik & 10 & 12,2 \\
Sikap & & \\
Kurang & 54 & 65,9
\end{tabular}

\begin{tabular}{lcc}
$\begin{array}{l}\text { Baik } \\
\text { Tindakan }\end{array}$ & 28 & 34,1 \\
Kurang & 52 & 63,4 \\
Baik & 30 & 36,6 \\
\hline Total & $\mathbf{8 2}$ & $\mathbf{1 0 0 , 0}$ \\
\hline \multicolumn{4}{c}{ Berdasarkan tabel } & dapat \\
dilihat jumlah siswa 82 orang. \\
Menunjukkan bahwa sebagian besar \\
Pengetahuan Sanitasi Dasar Kurang \\
yaitu sebanyak 72 siswa (87,8\%), \\
dan sebagian kecil Pengetahuan \\
Sanitasi Dasar Baik yaitu sebanyak \\
10 siswa (12,2\%). Sikap Sanitasi \\
Dasar siswa kategori kurang yaitu \\
sebanyak 54 siswa (65,9\%), dan \\
sikap baik yaitu sebanyak 28 siswa \\
(34,1\%). Tindakan PHBS yang \\
Kurang yaitu sebanyak 52 siswa \\
(63,4\%), dan sebagian kecil \\
tindakan PHBS yang Baik yaitu \\
sebanyak 30 siswa ( $36,6 \%)$.
\end{tabular}

Analisis Bivariat

Tabel 2. Hubungan Pengetahuan, Sikap dengan Tindakan Perilaku Hidup Bersih dan Sehat (PHBS) Siswa

\begin{tabular}{|c|c|c|c|c|c|c|c|c|}
\hline \multirow{3}{*}{ Variabel } & \multicolumn{6}{|c|}{ Tindakan PHBS } & \multirow{3}{*}{$\boldsymbol{P}$} & \multirow{3}{*}{ OR } \\
\hline & \multicolumn{2}{|c|}{ Baik } & \multicolumn{2}{|c|}{ Kurang } & \multicolumn{2}{|c|}{ Total } & & \\
\hline & $\mathbf{n}$ & $\%$ & $\mathbf{n}$ & $\%$ & $\mathbf{n}$ & $\%$ & & \\
\hline \multicolumn{9}{|c|}{ Pengetahuan } \\
\hline Baik & 7 & 70,0 & 3 & 30,0 & 10 & 100 & \multirow{2}{*}{0,046} & \multirow{2}{*}{2,269} \\
\hline Kurang & 23 & 31,9 & 49 & 68,1 & 72 & 100 & & \\
\hline \multicolumn{9}{|l|}{ Sikap } \\
\hline Baik & 15 & 53,6 & 13 & 46,4 & 28 & 100 & \multirow{3}{*}{0,040} & \multirow{3}{*}{1,556} \\
\hline Kurang & 15 & 27,8 & 39 & 72,2 & 54 & 100 & & \\
\hline Total & 30 & 36,6 & 52 & 63,4 & 82 & 100 & & \\
\hline
\end{tabular}

Berdasarkan tabel diatas diketahui mayoritas pengetahuan sanitasi dasar kurang dengan tindakaan PHBS kurang sebanyak 49 siswa $(68,1 \%)$ dan minoritas pengetahuan kurang dengan tindakaan baik sebanyak 23 siswa
$(31,9 \%)$ hasil distribusi antara pengetahuan sanitasi dasar dengan tindakan PHBS dan menggunakan uji Chi-square dengan nilai $P=0,046$. Hal ini menunjukkan terdapat hubungan antara pengetahuan sanitasi dasar 
dengan tindakan PHBS di SD Negeri 046579 Desa Lau Peranggunen Kab. Karo. Tindakaan PHBS kurang sebanyak 39 siswa $(72,2 \%)$ dan minoritas sikap kurang dengan tindakaan PHBS baik sebanyak 15 siswa $(27,8 \%)$ hasil distribusi antara sikap sanitasi dasar dengan tindakan PHBS dan menggunakan uji Chi-Square dengan $P=0,040$. Hal ini menunjukkan terdapat hubungan antara sikap sanitasi dasar dengan tindakan PHBS di SD Negeri 046579 Desa Lau Peranggunen Kab.Karo.

\section{Pembahasan}

\section{Hubungan Pengetahuan Sanitasi Dasar dengan Tindakan Perilaku Hidup Bersih Dan Sehat}

Berdasarkan penelitian untuk mengetahui hubungan pengetahuan tentang sanitasi dasar dengan tindakan PHBS di SD Negeri 046579 Desa Lau Peranggunen Kab.Karo yang telah diakukan dengan 82 siswa di ketahui siswa yang pengetahuan sanitasi baik dengan tindakan PHBS baik yaitu sebanyak 7 siswa (70,0\%), sedangkan pengetahuan sanitasi baik dengan tindakan PHBS kurang yaitu sebanyak 3 siswa $(30,0 \%)$ dan siswa yang pengetahuan sanitasi kurang dengan tindakan PHBS baik yaitu sebanyak 23 siswa $(31,9 \%)$ sedangkan peengetahuan sanitasi kurang dengan tindakan PHBS kurang yaitu sebanyak 49 siswa $(68,1 \%)$. Hal ini disebabkan oleh banyaknya siswa yang tidak mengetahui apa itu sanitasi dasar dan tidak menerapkan tindakan PHBS dengan baik
Berdasarkan analisis data yang dilakukan diperoleh nilai $p=0,046$ menunjukkan bahwa terdapat hubungan yang signifikan antara pengetahuan sanitasi dasar dengan tindakan PHBS siswa di SD Negeri 046579 Desa Lau Peranggunen Kab.Karo, kondisi ini disebabkan masih banyak siswa yang tidak mengetahu sanitasi dasar dan tidak melakukan tindakan PHBS.

Pengetahuan merupakan hasil dari tahu, dan ini terjadi setelah seseorang melakukan penginderaan terhadap suatu objek tertentu. Penginderaan terjadi melalui panca indera manusia, yakni melalui mata dan telinga. Pengetahuan adalah hasil tau atau kemampuan/ illmu yang dimiliki seseorang dan dapat digunakan kepada diri sendiri atau pun orang lain. Pengetahuan dapat diibaratkan sebagai suatu alat yang dipakai manusia dalam menyelesaikan persoalan yang dihadapi (Notoatmodjo, 2012).

\section{Hubungan Sikap Sanitasi Dasar dengan Tindakan Perilaku Hidup Bersih dan Sehat (PHBS)}

Dari hasil penelitian yang dilakukan untuk mengetahui hubungan sikap tentang sanitasi dasar dengan tindakan PHBS di SD Negeri 046579 Desa Lau Peranggunen Kab.Karo yang telah diakukan dengan 82 siswa di ketahui siswa yang sikap sanitasi baik dengan tindakan PHBS baik yaitu sebanyak 15 siswa $(53,6 \%)$, sedangkan sikap sanitasi baik dengan tindakan PHBS kurang yaitu sebanyak 13 siswa $(46,4 \%)$ 
dan siswa yang sikap sanitasi kurang dengan tindakan PHBS baik yaitu sebanyak 15 siswa $(27,8 \%)$ sedangkan sikap sanitasi kurang dengan tindakan PHBS kurang yaitu sebanyak 39 siswa (72,2\%). Berdasarkan analisis data yang dilakukan diperoleh nilai p 0,040, menunjukkan bahwa terdapat hubungan yang signifikan antara sikap sanitasi dasar dengan tindakan PHBS di SD Negeri 046579 Desa Lau Peranggunen Kab.Karo.

\section{Kesimpulan dan saran}

Terdapat hubungan pengetahuan dan sikap sanitasi dasar dengan tindakan PHBS di SD Negeri 046579 Desa Lau

Peranggunen Kab. Karo

Disarankan kepada Sekolah Untuk Menciptakan sekolah yang lebih bersih dan sehat, Perlu sosialisasi dan motivasi kepada siswa agar dapat meningkatkan kesadaran PHBS siswa. Disarankan kepada guru Guru harus terlibat dalam mendidik PHBS siswa setiap kelas. Diharapkan Guru menjadi model PHBS bagi siswa. Siswa diharapkan dapat meningkatkan perilaku hidup bersih dan sehat untuk mencegah penyakit.

\section{Daftar Pustaka}

Arikunto, S., 2009. Manajemen Penelitian.Jakarta:Rinekacipta.

Ariyanti Limpo. 2010. Prasarana Air Bersih.
Barens, joseph, 2014. Hubungan pengetahuan dan sikap dengan prilaku hidup bersih dan sehat.

Belliani B.B., Jootje M.L., Oksfriani J.S. 2018. Hubungan Antara Tingkat Pengetahuan Dan Sikap Dengan Tindakan Perilaku Hidup Bersih Dan Sehat Pada Murid Sekolah Dasar Gmim 9 Dan Sekolah Dasar Negeri Inpres Pinangunian Kota Bitung

Husein, Umar. 2010. Metode Penelitian Untuk Skripsi dan Tesis Bisnis Edisi 11. Jakarta: PT Raja Grafindo Persada

Kementrian Pendidikan dan Kebudayaan. 2012. Bahan Uji Publik Kurikulum 2013. Jakarta : Kementrian Pendidikan dan Kebudayaan.

Pramono, M. 2011. Peningkatan Pengetahuan tentang PHBS dan Penyakit Menular Melalui Teknik KIE Berupa Permainan Elektronik. Jurnal Buletin Penelitian Sistem Kesehatan Vol-14, No.4: 311-319

Kementrian Kesehatan RI. 2014. Profil Kesehatan Indonesia 2014.

Notoatmodjo, Soekidjo. 2003. Pendidikan Dan Perilaku Kesehatan. Rineka. Cipta. Jakarta 